\title{
Teaching Reform and Innovation of Engineering Training
}

\author{
Haijun Mo \\ South China University of Technology \\ Guangzhou,China \\ mohj@scut.edu.cn
}

\author{
Hua Jiang \\ South China University of Technology \\ Guangzhou,China
}

\begin{abstract}
Engineering training is a very important practicum in the universities of technology, which aim at cultivating students innovation thinking and practice ability. However, the engineering training is facing kinds of difficulties, such as how to make a scientific and optimized arrangement for the engineering training, how to reform and innovate engineering training and how to put training resources to rational distribute so as to make the students have an optimal training effect, get more reasonable and comprehensive practice. This paper has carried on the discussion and the research of problem confronting the universities. Some training items are recombined and optimized, rationally allocated. The aim is to make the students get more technical ability, better practice and creativity.
\end{abstract}

Key words- engineering training; refom; innovation

\section{INTRODUCTION}

Engineering training is a practical basic course of technology. It is an essential step in the professional teaching program concerning science and engineering. It is not only a compulsory course of manufacturability technology and engineering, but also an important site of comprehensive engineering quality education, modern manufacturing technology education, practical engineering training. Students can learn the basis and the concept of mechanical manufacture through practice. The basic scientific qualities, such as attitude about labor, consciousness of innovation, combination of theory and practice, can be cultivated and strengthened[1-5]. With the knowledge of manufacturing, the foundation for further study and future career can be built. All the high education institutions are competing to exploit resources so that their students can have more chances to practice[6-8]. However, as a national class experimental teaching engineering training center, the Engineering Training Center of South China University of Technology, we cannot deny the fact that our training programs are not scientifically set up, but they are out-of-date and repeatedly set. Besides, we do not have enough teaching staff, the arranging system is a chaos, and lack innovation. These facts prevent students from effective practice. We need to find out how to distribute training resources reasonably in order for students to gain practice effect in limited time. This essay analyses some big problems in engineering training, and reorganize and optimize the training program, so that students can receive more comprehensive and reasonable practice.

\section{CurRent Situation And EXISTing Problems}

Our school arrange more than 4,000 students for engineering training[9-10]. But the out-dated teaching method, lack of innovation, conflict between the number of students and the teaching resources are having a negative influence on the practice teaching, preventing the development of the engineering training center, even weakening the influence and competitiveness of our school. The problems mainly reflect in the following respects.

1) The type of work are too diverse and complicated. Currently, our training center provides more than 20 such trainings as cold working, hot working, and modern working. Some of the types are repeatedly set and inefficient.

2) The training programs are available to all the students of our school and the students of the branch schools in the Pearl River Delta. The students are from different majors. According to their professional features, 
they can be divided as mechanical majors, mechanical-relevant majors, and non-mechanical majors. They also have different practice periods, from 2 weeks on to 6 weeks.

3) The teaching resources are different. The quality of tutors and equipment are different. The conflict between new and old craftsmanship, the conflict between increasing number of students and the shortage of tutors are to be solved.

4) The training programs are chaotic. They have no focus, and they are not arranged according to the professional features different majors; the training of mechanical majors, mechanical-relevant majors, and non-mechanical majors are almost the same. In addition, the programs are not taking into account the practice period. So far, the main difference of practice in different majors is time. The practice process is not relevant to the profession, nor is it in accordance of students' aptitude. In most cases, the students just copy what the teacher did, lacking the cultivation of competence and effective measures.

5) The conflict between number of trainee and shortage of teaching equipment is not solved. Due to the increase enrollment, more and more students need engineering training. On the other hand, current teaching resources cannot keep pace with the development of the school. This lead to the tense between the number of trainee and the teaching equipment.

6) The number of trainee and tutor are mismatching. The change in school policy disables the training center to introduce high quality talents. For instance, talents with years of experience but low education background cannot get into school. In the meanwhile, retired teachers are increasing, so the school is understaffed. Therefore, the problem between the number of trainee and tutor intensifies.

7) The problem between traditional teaching mold and new teaching method. Currently, the engineering training is still adopting traditional craftsmanship which is behind industrial production level and cannot adapt to modern manufacture level. Some promising new material, new technology and new craftsmanship are not brought into practice timely. Existing training mold is not in accordance to the spirit of reform in high education[11-12].

Hence, the biggest problem in engineering training is how to optimize the efficiency under the pressure that teaching resources are limited, students are too many, professions and practice periods are different.

\section{MeAsures To Optimize EngineERING TRAining} PROGRAM

To optimize engineering training program, we need to build up scientific, reasonable and thorough course scheduling system in accordance to professional features, training period, the number of students, equipment and teaching resources[13-14].

1) Modularize training programs. Simplify complicated projects, cancel out-dated projects, and combine similar projects. The program can be divided into fundamental training, comprehensive training, and innovation training. For instance, grinding, milling, lathe, shaper can be classify as mechanical module. In the meanwhile, reasonably arrange old and new equipment, traditional training program and new technology in order to optimize the teaching resources in the training center.as shown in Table 1.

Table 1.

\begin{tabular}{|l|l|l|}
\hline \multicolumn{3}{|c|}{ Engineering training items } \\
\hline Basic training & Synthetical training & \multicolumn{1}{|c|}{ Enhance and } \\
module & & module \\
& & 1. Robot control \\
1. Mechanical & 1. Automotive & 2. reverse \\
processing & Technology & engineering \\
2. Hot processing & 2. Industrial control & technology \\
3. Industrial safety & 3. Laser processing & 3. Innovation \\
& 4. Electrospark & technology \\
\hline
\end{tabular}

Arrange training program according to different professional features, different training period to optimize the program. Mechanical majors and mechanical-relevant majors can have higher level trainings because they have longer training period and they have the knowledge needed. 
Therefore, their training period can be divided into two stages: in the first 4 weeks they are to have basic training, in the latter 2 weeks they can have innovative training, and carry out "Jingong Cup" innovative match which is a school activity set for mechanical majors. In the last 2 weeks, students are to design their own works. In this approach, students have clear goals and their enthusiasm can boost them to innovate. During the making of the prototype, students can design freely. They can draw their own blueprint, manufacture the parts, fit them together and finish the work.

Figure 1: The innovation products of students.
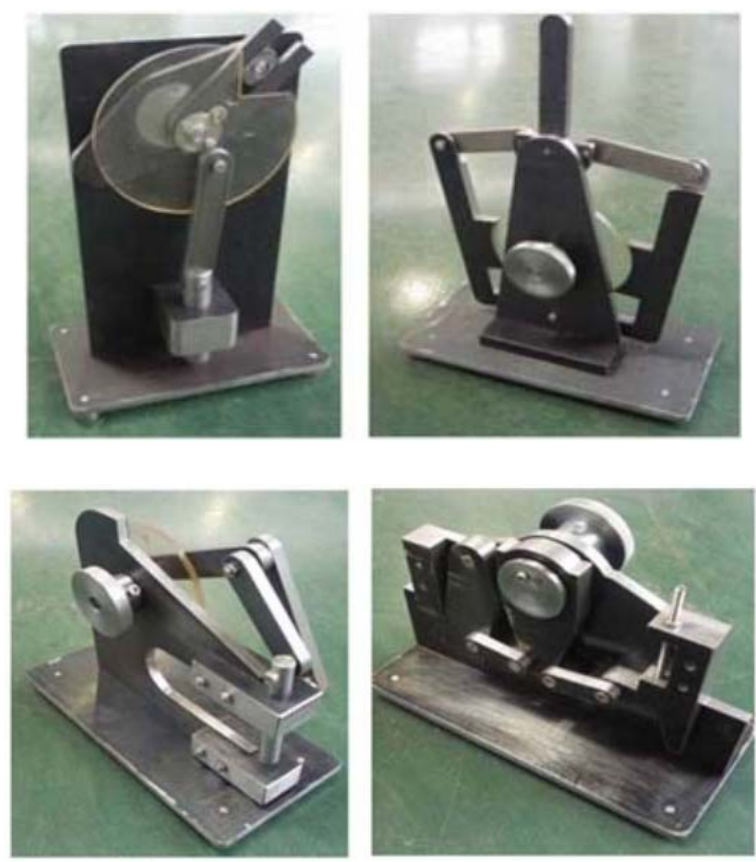

As for non-mechanical majors, they only have 2 weeks to practice and the number of students is gigantic and their professions are diverse. Thus, it is difficult for them to finish all types of practice in a short time. But they can focus on cognitive engineering. First, they can have basic training and then arrange more targeted practice according to their professional features. This enables the students to learn the basis of numerical control process technology, reverse engineering techniques, which are advanced modern processing technologies[15].

2) With regard to the shortage of tutors, the center should stress on the training on tutors. Vacations should be used for training in order to improve teaching arts. This has been put into practice for a few years and now, more than $40 \%$ of the tutors have senior technician qualification. Another $33 \%$ of the tutors are skilled technicians who can operate the machining center, numerical control machine tool, and the CNC milling machine. Some tutors can instruct students on grinding, milling, lathe, and shaper. Arranging personnel reasonably can effectively solve the problem of tutor shortage. In the meantime, tutors take the lead in innovative teaching. Tutors should make full use of existing equipment to create more chances for students to practice and to innovate, cultivate their consciousness of innovation, and encourage them to innovate.

3) Make use of the advantage in teaching, experimenting and demonstrating to develop new craftsmanship programs. Our school has develop reverse engineering training program based on 3D printing, laser processing technology, industrial control technology, surface treatment technology and robot technology. It is guaranteed that the time for studying advanced technology occupies $25 \%-30 \%$ of the whole period of training.

4) Focus on turning research result into teaching experience. Teachers are encouraged to turn research result into engineering training program in order for students to learn the process of production in the training. In the meantime, 3-4 advanced comprehensive innovative training are being developed to increase the competitiveness and influence of our school.

\section{CONCLUSION}

This essay analyses the problems existing in the teaching of engineering training and puts forward some solutions for the reform of traditional teaching methods. It is suggested that the training projects should be modulated and be in accordance to students' professional features, training period. Innovative design should be added to the training of mechanical majors and mechanical-relevant majors. In the design of innovative works, students' practical skills can be largely increased and the training can be more efficient. 


\section{REFERENCES}

[1] Hairong Fang , Jiangping Hong, Measures to Build a High Level Experimental Teaching Center of Mechanical Engineering [J],Experiment Technology and Management, 2014(31): 112-114.

[2] Qingchun Hu, Haijun Mo. Innovative Design and Making Course of Machinery Manufacturing Engineering Training[M],Guangzhou: South China University of Technology,2013.

[3] Bin Yang, Zhenyu Wang. Exploring and Practicing of Engineering Training Educational Reforms Based on Production[J],Research and exploration in laboratory.2013( 3 2): 189-192.

[4] Xiaodong Hu, Xuehua Li. A Probe of Engineering Training Instruction at universities of Technology, Journal of Shandong University of Science and Technology(Social Sciences), [J]. 2012 (14): 95-99.

[5] Qi Ggo, Zongyan Liu. A Probe into The Innovative Practical Education in Engineering Training, ,Research and exploration in laboratory. 2010 (10): 34-36.

[6] Zhijun Zheng , Songmao Chen. Improvement Engineering Practical Ability of Undergraduates by Combining Extracurricular Activities for Innovation[J], Experiment Technology and Management, 2014 (8): 25-27.

[7] Qingchun $\mathrm{Hu}$, Zhijun Zheng.Exploration of Increasing Ability of Engineering Practice to Mechanical Engineering major Student[J], Experiment Technology and Management, 2013 (4): 84-86.

[8] Xincheng $\mathrm{Xu}$, Jianjun Zhu.The Teaching Reform Exploration of Engineering Training for "The Plan of Excellent Engineer Education" [J],Research and exploration in laboratory,2014,33(5): 223-225.

[9] Hua Liu, Bo Wu.Construction and Practice on Multilevel and Open Engineering Training Teaching System Experiment[J], Science and Technology, 2011,10(1): 134-137.

[10] Yanhong Zuo, Keren Zhang.An Open Engineering Training System under Complete Credit System[J], Research and exploration in laboratory.2013,32 (1): 143-146.

[11] Shuguo Zhang, Jiaxuan Wang.Project-based Teaching Mode of Engineering Training $[\mathrm{J}]$, Research and exploration in laboratory,2012,31 (7): 307-309.

[12] Deming Liu.Establishment of Metalworking Practice Teaching Quality Guarantee System [ $\mathrm{J}]$,Research and Exploration in Laboratory,2009,(4): 113-116.

[13] Xiaochun Li, Xiaohai Qu.Exploration and Practice of the Engineering Training Teaching Reform[J], Research and exploration in laboratory,2014,33 (1): 230-232.

[14] Wei Wang.On the Quest and Practice of Engineering Training Teaching reform in University of Science and Technology[J], Journal of Nanjing University of Aeronautics Astronautics(Social Sciences) ,2009,11 (4): 89-91.

[15] Fenglian Song, Meiqing Liu.Exploration and Practice of the Research-oriented Engineering Training[J], Experiment Technology and Management, 2008,25 (7): 115-120. 